\title{
3 Research Square

\section{Isolated Progressive Enlargement of Head Mass as the First Symptom: A Rare Case Report of Cranial Metastasis of Hepatocellular Carcinoma and Literature Review}

\author{
Yuan-yuan Liu \\ Anhui Medical College: Anhui Medical University \\ Zhi-hua Zhou \\ Wuxi First People's Hospital: Wuxi People's Hospital \\ Shuai Hu \\ Anhui Medical College: Anhui Medical University

\section{Xin Su} \\ Anhui Medical College: Anhui Medical University \\ jinxu zhou ( $\nabla$ zjinxu1979@163.com ) \\ Wuxi First People's Hospital: Wuxi People's Hospital
}

\section{Case report}

Keywords: skull metastasis, hepatocellular carcinoma, bone metastasis

Posted Date: June 28th, 2021

DOl: https://doi.org/10.21203/rs.3.rs-625862/v1

License: (1) This work is licensed under a Creative Commons Attribution 4.0 International License. Read Full License 


\section{Abstract}

Background: This article presents a rare case of skull metastasis of primary hepatocellular carcinoma that manifests the isolated progressive enlargement of the head mass as the first symptom.

Case presentation:A 65-year-old female patient presented an isolated painless mass in the head, which grew rapidly over the last month. Head CT revealed a $6.4 \mathrm{~cm} \times 5.6 \mathrm{~cm}$ osteolytic destruction in the right parietal bone. MRI further revealed that the occupation was significantly enhanced in the T1 reinforced phase. The patient underwent total surgical resection. Postoperative pathology confirmed that the head mass was the skull metastasis from hepatocellular carcinoma (HCC).

Conclusion: The case of skull metastasis from primary hepatocellular carcinoma is rare, and HCC patient with intracranial metastasis tends to have a rather poor prognosis. Surgical excision of the metastatic mass and radiotherapy can improve the life quality and prolong the survival time of the patient.

\section{Background}

Hepatocellular carcinoma rarely metastasizes to the bone system, as the reported incidence of skull metastases is as low as about 0.5 to 1.6 percent $^{1,2}$. Consistently, the case of progressive enlargement of isolated head mass as the first symptom for HCC is extremely rare ${ }^{3,4}$. Here, we report a case of skull metastasis of hepatocellular carcinoma, and conduct the literature review.

\section{Case Description}

A 65-year-old female patient admitted to the neurosurgery department of our hospital was diagnosed with an isolated progressive enlargement head mass. Over the past six months before admission, she occasionally felt dizzy. Three months before admission, the patient accidentally found a mass in the right parietal bone during the haircut. One month before admission, the patient felt that the mass had been enlarged significantly. About one week before admission, the mass was several times larger than the size of 3 months ago. The patient reported a history of hypertension for 15 years, an event of acute appendicitis 30 years ago and received appendectomy. She also underwent surgery of Lumbar disc herniation 23 years ago.

\section{After Admission:}

\section{Physical examination}

A solitary painless head mass (about $6.4 \mathrm{~cm} \times 5.6 \mathrm{~cm}$ in diameter) was observed in her right parietal region. The other physical examination did not confirm hepatic disease-related signs, such as liver palm, spider nevus

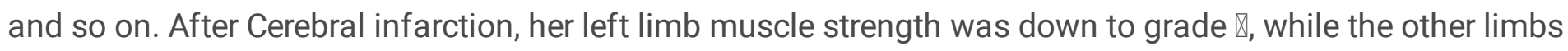
remained normal.

\section{Laboratory examination}


Alanine aminotransferase (ALT) was $83 \mathrm{U} / \mathrm{L}$ (normal value 0-50 U/L). In addition, other laboratory indicators, including liver function, coagulation function and so on, were normal.

\section{Image examination}

B ultrasound test found that the subcutaneous soft tissue in the range of about $67 \times 25 \mathrm{~mm}$ was hypoechoic, the boundary was unclear, the local skull bone cortex continuity was interrupted. Moreover, the internal signal showed a $53 \times 26 \mathrm{~mm}$ hypoechoic zone, along with the external hypoechoic rim. The findings indicated that the head subcutaneous soft tissue is hypoechoic, and the possibility of hematoma should be considered.

Abdominal B ultrasound revealed fatty liver, and no space-occupying lesions could be determined in gallbladder, pancreas, and spleen. Skull CT examination showed that the right parietal bone was destroyed and a soft tissue mass sized about $6.4 \times 5.6 \mathrm{~cm}$ was (Fig. 1). MRI examination showed that the right parietal bone destruction and surrounding soft tissue mass (about $6.4 \times 5.6 \mathrm{~cm}$ in size) with uneven enhancement. (Fig. 2).

Treatment: The patient accepted the resection of the space-occupying lesion in the right hemisphere. Sarcomatous tumor located outside the epidural was determined by intraoperative pathological analysis. The tumor had invaded the surface of the superior sagittal sinus. Then we resected the tumor completely, and found that the tumor capsule was intact, and that the cut surface was like beige fish. Postoperative immunohistochemistry suggested: GFAP (-). SYN (-). AE1/AE3(+). SOX10(-). CGA (-). VIM (-). CD99(-). TFE3(-). Ki-67(30\%+). CK18(+). CK19(-). P63(-). TTF1(-). CD56(-). CEA (-). SMA (-). PAX8(-). GATA3(-). TG (-). HMB45(-). CK7(-). CK20(-). HePpar-1(+). GPC-3(+). CD34(-). ERG (-). SALL4(-). SYN (-). S100(-). The results of Immune markers were in agreement with the diagnosis of metastatic hepatocellular carcinoma, and the proliferation of cancer cells was medium (Fig. 3).

Postoperative pathology showed a convex oblate mass sized of $6.7 \times 6.7 \times 2 \mathrm{~cm}$, whose section was gray yellow and solid. Apparently, the mass seemed to have a capsule. Microscopic analysis showed that the tumor tissue has a dense arrangement, and forms the solid cancer nest and adenoid structure. A large number of blood sinuses could be seen in the stroma, which was indicative of hepatocellular metastatic carcinoma. All the tumor cells were consistently round in shape (Fig. 4).

The abdominal CT plain scan and enhancement examination found primary liver occupation (Fig. 5);

Postoperative laboratory examination indicated that the expression of liver tumor markers, including carbohydrate antigen 125,199 , carcinoembryonic antigen, alpha fetoprotein, was still within the normal range.

\section{Discussion And Conclusions}

The patients with hepatocellular carcinoma usually had a dismal prognosis ${ }^{5}$. The short therapeutic time window for extrahepatic metastases is usually in the late stages ${ }^{6}$. The common sites of extrahepatic metastasis of hepatocellular carcinoma include regional lymph nodes, lungs, bones and so on ${ }^{7}$. Among them, hepatocellular carcinoma bone metastasis often occurs in vertebrae, pelvis, ribs, skull and so on ${ }^{5}$. Previous literatures reported that the incidence of skull metastasis in hepatocellular carcinoma was roughly 
$0.5 \%-1.6 \% 8,9$. The prognosis of patients with skull metastasis of hepatocellular carcinoma was poor and the overall survival time was notoriously short in an average of 8 to 9 months ${ }^{10}$. In this case, the surgical indication was clear due to severe destruction of skull bone and infiltration of the sagittal sinus induced by the tumor ${ }^{11}$. Of note, the patient only manifested isolated and progressive enlargement head mass as the first symptom, and there was no obvious abnormality in the expression of the liver and tumor markers. After the surgical operation, only abdominal enhancement CT suggested that the left lobe of the liver is occupied.

A thorough searching of the literature in a vast variety of languages was performed to find all the available articles that describe skull metastasis from hepatocellular carcinoma, since January $1957^{12-62}$, one hundred and seven articles with the keywords of "skull metastasis AND hepatocellular carcinoma", 35 articles with "((skull metastasis [All Fields])) AND (hepatocellular carcinoma)" were found. These studies formed the basis of this review (Table 1). We found that the cases of cranium metastases from hepatocellular carcinoma were much prevalent than that of skull base metastasis, and such disparity could be attributable to the difficulty to find or to diagnose the skull base metastasis. More cases have been reported in recent years, partly due to the prolonged life expectancy of the population and the development of diagnosis technology ${ }^{63}$.

In light of the diagnosis and treatment of the patients with skull metastasis from hepatocellular carcinoma in this case, the author puts forward the following suggestions. Firstly, in terms of the diagnosis of progressive enlargement of scalp mass, if CT examination suggests osteolytic destruction of the skull, MRI examination further revealed that the occupation was significantly enhanced in T1 reinforced phase, with equal or low signal in $\mathrm{Tl}$ and $\mathrm{T} 2$ image, then the possibility of malignant tumor skull metastasis should be considered ${ }^{64}$. Secondly, in terms of clinical intervention, given the poor prognosis of patients with skull metastasis of hepatocellular carcinoma is poor ${ }^{4}$, the treatment regimens should be individualized by the combined therapy of surgical removal, radiotherapy, palliative treatment and so on ${ }^{1}$. Thirdly, in terms of operation, since the tumor tissue has an abundant blood supply ${ }^{65}$, blood (including blood products associated with coagulation) should be prepared before surgery to prevent significant intraoperative bleeding. In this case, a large amount of bleeding began after scalp incision.

Based on the review of these cases, we find that skull metastasis from hepatocellular carcinoma a rare case $^{63}$, and that the symptom of cranial metastasis of primary hepatocellular carcinoma is no specific. The liver function may not be compromised significantly, and the patient has no specific signs. When dealing with cases of a head mass that rapidly increases within the short term and shows osteolytic bone destruction by CT examination, we should consider skull metastasis as the potential diagnosis ${ }^{65}$. An early and active intervention can improve the life quality and prolong the overall survival time of the patient ${ }^{66}$.

\section{Declarations}

\section{Ethics approval and consent to participate}

We confirm that any aspect of the work covered in this manuscript that has involved human patients has been conducted with the ethical approval of all relevant bodies. 
Written informed consent has been obtained from the patient to have case details and any accompanying images published.

\section{Consent for publication}

Written informed consent for publication was obtained from all participants.

\section{Availability of data and materials}

The datasets used or analysed during the current study are available from the corresponding author on reasonable request.

\section{Competing interests}

The authors report no conflicts of interest in this work.

\section{Funding}

This work was supported by grants from Scientific research project of Wuxi health commmission, China \Z201803囚

\section{Author contributions}

All authors contributed to data analysis, drafting and revising the article, gave fifinal approval of the version to be published, and agree to be accountable for all aspects of the work.

\section{Acknowledgements}

Written consent was obtained from the patient for publication of this case report.

\section{Authors' information (optional)}

Yuan-yuan Liu ${ }^{1,2}$, Zhi-hua Zhou ${ }^{3}$, Shuai Hu ${ }^{1}$, Xin Su ${ }^{1}$, Jin-xu Zhou ${ }^{1,2,3}$

${ }^{1}$ Department of Neurosurgery, Wuxi Clinical School of Anhui Medical University, Wuxi,214044, China

${ }^{2}$ Department of Neurosurgery, The Fifth Clinical Medical College of Anhui Medical University, Wuxi,214044, China

${ }^{3}$ Department of Neurosurgery, The 904th Hospital of Joint Logistic Support Force of PLA, Wuxi, 214044, China Corresponding author, Jin-xu Zhou, Email: zxh071109@sina.cn

\section{References}

1. Hsieh CT, Sun JM, Tsai WC, Tsai TH, Chiang YH, Liu MY. Skull metastasis from hepatocellular carcinoma. Acta Neurochir (Wien). 2007;149(2):185-90. doi:10.1007/s00701-006-1071-3.

2. Mclver JI, Scheithauer BW, Rydberg CH, Atkinson JL. Metastatic hepatocellular carcinoma presenting as epidural hematoma: case report. Neurosurgery. 2001;49(2):447-9. doi:10.1097/00006123-200108000- 
00034.

3. Shim YS, Ahn JY, Cho JH, Lee KS. Solitary skull metastasis as initial manifestation of hepatocellular carcinoma. World J Surg Oncol. 2008;6:66. doi:10.1186/1477-7819-6-66. Published 2008 Jun 21.

4. Chan $\mathrm{CH}$, Trost N, McKelvie P, Rophael JA, Murphy MA. Unusual case of skull metastasis from hepatocellular carcinoma. ANZ J Surg. 2004;74(8):710-3. doi:10.1111/j.1445-1433.2004.02961.x.

5. Sadik KW, Dayoub H, Bonatti H. Superior Sagittal Sinus Tumor Eroding through the Skull: An Unfamiliar Presentation of Hepatocellular Carcinoma and Literature Review. Case Rep Surg. 2019;2019:5945726. Published 2019 Nov 4. doi:10.1155/2019/5945726.

6. Stark AM, Eichmann T, Mehdorn HM. Skull metastases: clinical features, differential diagnosis, and review of the literature. Surg Neurol. 2003;60(3):219-26. doi:10.1016/s0090-3019(03)00269-6.

7. Ferraz VR, Vitorino-Araújo JL, Sementilli L, Neto JF, Veiga JC. Lesion in Scalp and Skull as the First Manifestation of Hepatocellular Carcinoma. Case Rep Neurol Med. 2016;2016:2897048. doi:10.1155/2016/2897048.

8. Han S, Zhang XH, Lv T, Han DH. Skull Metastasis from the Liver: Case Report and Literature Review. World Neurosurg. 2017;108:989.e15-989.e18. doi:10.1016/j.wneu.2017.08.104.

9. Susheela SP, Revannasiddaiah S, Basavalingaiah AS, Madabhavi I. Painless lump over the forehead which turned painful: an unusual presentation of hepatocellular carcinoma. BJR Case Rep. 2015;1(2):20150033. Published 2015 May 18. doi:10.1259/bjrcr.20150033.

10. Goto T, Dohmen T, Miura K, et al. Skull metastasis from hepatocellular carcinoma with chronic hepatitis B. World J Gastrointest Oncol. 2010;2(3):165-8. doi:10.4251/wjgo.v2.i3.165.

11. Uei $H$, Tokuhashi $Y$, Maseda $M$, et al. Surgical management of coincidental metastases to upper cervical spine and skull from hepatocellular carcinoma: a case report. J Int Med Res. 2018;46(11):4852-9. doi:10.1177/0300060518800875.

12. Sochat MM, Piao J, Poddar N. Hepatocellular Carcinoma with Orbital Metastasis: a Unique Multidisciplinary Case Report. J Gastrointest Cancer. 2019;50(4):978-82. doi:10.1007/s12029-018-01593.

13. Lei Q, Chen $\mathrm{H}$, Zheng $\mathrm{H}$, et al. Zygomatic bone metastasis from hepatocellular carcinoma and the therapeutic efficacy of apatinib: A case report and literature review. Med (Baltim). 2019;98(18):e14595. doi:10.1097/MD.0000000000014595.

14. Cathel A, Khan YR, Blais D, Mahato B, Mahato D. Metastatic Disease to Clivus: Biopsy or Not? Cureus. 2019;11(9):e5658. doi:10.7759/cureus.5658. Published 2019 Sep 14.

15. Chaudhary D, Patkar S, Shrikhande SV, Goel M. Metastasis from Hepatocellular Carcinoma Masquerading as a Jugular Paraganglioma. J Gastrointest Cancer. 2018;49(4):517-9. doi:10.1007/s12029-017-9943-8.

16. Geske MJ, Bloomer MM, Kersten RC, Vagefi MR. Diagnostic Approaches to Metastatic Hepatocellular Carcinoma of the Orbit. Ophthalmic Plast Reconstr Surg. 2017;33(3S Suppl 1):129-31. doi:10.1097/IOP.0000000000000641.

17. Kim YS, Moon KS, Lee KH, et al. Spontaneous acute epidural hematoma developed due to skull metastasis of hepatocelluar carcinoma: A case report and review of the literature. Oncol Lett. 2016;11(1):741-4. doi:10.3892/ol.2015.3947. 
18. Chye CL, Lin KH, Ou CH, Sun CK, Chang IW, Liang CL. Acute spontaneous subdural hematoma caused by skull metastasis of hepatocellular carcinoma: case report. BMC Surg. 2015;15:60. Published 2015 May 10. doi:10.1186/s12893-015-0045-x.

19. Klasser GD, Echandi L, Shannon M. Hepatocellular carcinoma metastasis to the condyle: a case report and review of the literature. J Am Dent Assoc. 2014;145:1063-7.

20. Guo X, Yin J, Jiang Y. Solitary skull metastasis as the first symptom of hepatocellular carcinoma: case report and literature review. Neuropsychiatr Dis Treat. 2014;10:681-6.

21. Azarpira N, Dehghanian A, Safarian A, Kazemi K. Case report of skull metastasis from hepatocellular carcinoma after a liver transplant. Exp Clin Transplant. 2014;12(3):265-8. doi:10.6002/ect.2013.0019.

22. Nemetz U, Tomazic PV, Walch $\mathrm{C}$, et al. Pyramidal apex metastasis as primary manifestation of hepatocellular carcinoma. Otol Neurotol. 2013;34(4):e30-1. doi:10.1097/MA0.0b013e318271c34a.

23. Turan I, Yapali S, Ozutemiz O, Karasu Z. Frontal skull metastasis extending through the scalp: initial sign of hepatocellular carcinoma recurrence 5 years after liver transplantation. Transplantation. 2013;95:e156.

24. Tomanovic N, Krstic A, Brasanac D, Dimitrijevic M, Terzic T, Boricic I. Zygomatic bone metastasis as an initial presentation of hepatocellular carcinoma. Arch Iran Med. 2013;16(11):675-8.

25. Miller ME, McCall AA, Juillard GF, Nadelman CM, Wang MB, Nabili V. Hepatocellular carcinoma metastatic to the mandible. Ear Nose Throat J. 2013;92(2):E17-9.

26. Brunetti AE, Popescu O, Silvestris N. Synchronous mandibular and giant parieto-occipital skull metastasis from hepatocellular carcinoma. Clin Gastroenterol Hepatol. 2013;11(2):xxvi. doi:10.1016/j.cgh.2012.08.028.

27. Sánchez-Delgado J, Calzado S, de Haro C, et al. Larga supervivencia tras resección de metástasis craneal de hepatocarcinoma. Descripción de un caso y revisión de la literatura [Long survival after resection of cranial metastases from hepatocellular carcinoma. Case report and review of the literature]. Gastroenterol Hepatol. 2012;35(1):12-6. doi:10.1016/j.gastrohep.2011.11.002.

28. Ermis F, Dursun M, Kurt R, Akyuz F. Skull metastasis from hepatocellular carcinoma with hepatitis C. Ann Saudi Med. 2012;32(3):321-2. doi:10.5144/0256-4947.2012.321.

29. Yang JI, Kang JM, Byun HJ, et al. Metastatic hepatocellular carcinoma presenting as facial nerve palsy and facial pain. Korean J Hepatol. 2011;17(4):319-22. doi:10.3350/kjhep.2011.17.4.319.

30. Ito J, Saito T, Iwaba A, et al. A case of monocular blindness as the initial presentation of hepatocellular carcinoma with skull metastasis. Clin J Gastroenterol. 2011;4(4):273-7. doi:10.1007/s12328-011-02376.

31. Woo KM, Kim BC, Cho KT, Kim EJ. Spontaneous epidural hematoma from skull base metastasis of hepatocellular carcinoma. J Korean Neurosurg Soc. 2010;47(6):461-3. doi:10.3340/jkns.2010.47.6.461.

32. Bair MJ, Lei WY, Chen CL. Electronic images of the month. An unusual presentation of hematemesis: a presentation of maxillary metastasis from hepatocellular carcinoma. Clin Gastroenterol Hepatol. 2010;8(6):e61-2. doi:10.1016/j.cgh.2009.12.028.

33. Trivedi P, Gupta A, Pasricha S, Agrawal G, Shah M. Isolated skull base metastasis as the first manifestation of hepatocellular carcinoma-a rare case report with review of literature. J Gastrointest 
Cancer. 2009;40(1-2):10-4. doi:10.1007/s12029-009-9081-z.

34. Kamatani T, Tatemoto Y, Tateishi Y, Yamamoto T. Isolated metastasis from hepatocellular carcinoma to the mandibular condyle with no evidence of any other metastases: a case report. Br J Oral Maxillofac Surg. 2008;46(6):499-501. doi:10.1016/j.bjoms.2008.01.001.

35. Hsu SY, Chang FL, Sheu MM, Tsai RK. Homonymous hemianopia caused by solitary skull metastasis of hepatocellular carcinoma. J Neuroophthalmol. 2008;28(1):51-4. doi:10.1097/WNO.0b013e3181675438.

36. Kim SJ, Kim HJ, Lee HW, et al. Hepatocellular carcinoma with metastasis to the cavernous sinus of skull base causing ptosis. Korean J Gastroenterol. 2008;52(6):389-93.

37. Hirunwiwatkul P, Tirakunwichcha S, Meesuaypong P, Shuangshoti S. Orbital metastasis of hepatocellular carcinoma. J Neuroophthalmol. 2008;28(1):47-50. doi:10.1097/WNO.0b013e31816754e7.

38. Huang SF, Wu RC, Chang JT, et al. Intractable bleeding from solitary mandibular metastasis of hepatocellular carcinoma. World J Gastroenterol. 2007;13(33):4526-8. doi:10.3748/wjg.v13.i33.4526.

39. Kim SR, Kanda F, Kobessho H, et al. Hepatocellular carcinoma metastasizing to the skull base involving multiple cranial nerves. World J Gastroenterol. 2006;12(41):6727-9. doi:10.3748/wjg.v12.i41.6727.

40. Escarda A, Vaquer P, Bonet L, Miralbés S, Gómez C, Obrador A. Metástasis en clivus de hepatocarcinoma asociado a quimiembolización transarterial hepática [Clivus metastasis from hepatocarcinoma associated with transarterial hepatic chemoembolization]. Gastroenterol Hepatol. 2006;29(7):401-4. doi:10.1157/13091453.

41. Nam SW, Han JY, Kim JI, et al. Spontaneous regression of a large hepatocellular carcinoma with skull metastasis. J Gastroenterol Hepatol. 2005;20(3):488-92. doi:10.1111/j.1440-1746.2005.03243.x.

42. De Simone P, Carrai P, Morelli L, et al. Posttransplant hepatocellular carcinoma metastasis at a skull trauma site. Transplantation. 2005;80(9):1358-9. doi:10.1097/01.tp.0000179155.90423.dc.

43. Jegou J, Perruzi P, Arav E, Pluot M, Jaussaud R, Remy G. Métastases mixtes cutanéo-osseuses révélatrices d'un carcinome hépatocellulaire [Cutaneous and bone metastases revealing hepatocarcinoma]. Gastroenterol Clin Biol. 2004;28(8-9):804-6. doi:10.1016/s0399-8320(04)95132-9.

44. Aung TH, Po YC, Wong WK. Hepatocellular carcinoma with metastasis to the skull base, pituitary gland, sphenoid sinus, and cavernous sinus. Hong Kong Med J. 2002;8(1):48-51.

45. Torres M, Alvarez R, López D, Titó L. Hepatocellular carcinoma skull metastasis with both extradural and subcutaneous extension. J Hepatol. 2002;36(4):569. doi:10.1016/s0168-8278(02)00033-8.

46. Neff BA, Pribitkin EA, Willcox TO Jr. Hepatocellular cancer metastatic to the zygoma: primary resection and immediate reconstruction. Ear Nose Throat J. 2002;81(1):57-8.

47. Kleinjung T, Held P. Metastase eines Leberzellkarzinoms in der Rhinobasis [Metastasis in the frontal skull base from hepatocellular carcinoma]. HNO. 2001;49(2):126-9. doi:10.1007/s001060050721.

48. Hayashi K, Matsuo T, Kurihara M, Daikoku M, Kitange G, Shibata S. Skull metastasis of hepatocellular carcinoma associated with acute epidural hematoma: a case report. Surg Neurol. 2000;53(4):379-82. doi:10.1016/s0090-3019(00)00208-1.

49. Isaka T, Yoshimine T, Fujimoto K, et al. Direct ethanol injection for skull metastasis from hepatocellular carcinoma. The techniques and consequences of a therapeutic trial. Neurol Res. 1998;20(8):737-41. doi:10.1080/01616412.1998.11740593. 
50. Raoul JL, Le Simple T, Le Prisé E, Meunier B, Ben Hassel M, Bretagne JF. Bone metastasis revealing hepatocellular carcinoma: a report of three cases with a long clinical course. Am J Gastroenterol. 1995;90(7):1162-4.

51. Rosa JC, Chaves P, de Almeida JM, Soares J. Carcinoma hepato-celular. Formas de apresentação raras [Hepatocellular carcinoma. Rare forms of presentation]. Acta Med Port. 1995;8(4):243-5.

52. Yen FS, Wu JC, Lai CR, et al. Clinical and radiological pictures of hepatocellular carcinoma with intracranial metastasis. J Gastroenterol Hepatol. 1995;10(4):413-8. doi:10.1111/j.14401746.1995.tb01593.x.

53. Tranfa F, Cennamo G, Rosa N, De Rosa G, Boscaino A, Bonavolontà G. An unusual orbital lesion: hepatoma metastatic to the orbit. Ophthalmologica. 1994;208(6):329-32. doi:10.1159/000310532.

54. Yoshida D, Chen MN, Awaya S, Nakazawa S. Cranial metastasis of hepatocellular carcinoma in a female-case report. Neurol Med Chir (Tokyo). 1993;33(12):839-44. doi:10.2176/nmc.33.839.

55. Nakagawa Y, Yoshino E, Suzuki K, Tatebe A, Andachi H. Spontaneous epidural hematoma from a hepatocellular carcinoma metastasis to the skull-case report. Neurol Med Chir (Tokyo). 1992;32(5):3002. doi:10.2176/nmc.32.300.

56. Otsuka N, Fukunaga M, Morita K, et al. Accumulation of 99mTc-HM-PAO in photon deficient areas in bone scan of bone metastasis from hepatocellular carcinoma. Ann Nucl Med. 1992;6(4):215-20. doi:10.1007/BF03164657.

57. Nakao N, Kubo K, Moriwaki H. Cranial metastasis of hepatocellular carcinoma associated with chronic epidural hematoma-case report. Neurol Med Chir (Tokyo). 1992;32(2):100-3. doi:10.2176/nmc.32.100.

58. Miura T, Hirabuki N, Kozuka T. Cranial metastasis from hepatocellular carcinoma. Clin Radiol. 1990;42(6):445-6. doi:10.1016/s0009-9260(05)80905-5.

59. Kuratsu J, Murakami M, Uemura S, Ushio Y. Brain and skull metastases of hepatic or pancreatic cancerreport of six cases. Neurol Med Chir (Tokyo). 1990;30(7):476-82. doi:10.2176/nmc.30.476.

60. Nakao S, Sato S, Fukumitsu T, Ogata M, Shirane H. Neurol Med Chir (Tokyo). 1985;25(3):229-34. doi:10.2176/nmc.25.229.

61. DICK A, MEAD SG, SCHATTEN MENSHM WE. Primary hepatoma with metastasis to the mandible. Am J Surg. 1957;94(6):846-850. doi:10.1016/0002-9610(57)90068-585.Fukushima M, Katagiri A, Mori T, Watanabe T, Katayama Y. No Shinkei Geka. 2010;38(4):371-377.

62. Chang JW, Howng SL. Skull metastasis of primary hepatoma-case report. Gaoxiong Yi Xue Ke Xue Za Zhi. 1991;7(12):657-62.

63. Guo X, Yin J, Jiang Y. Solitary skull metastasis as the first symptom of hepatocellular carcinoma: case report and literature review. Neuropsychiatr Dis Treat. 2014;10:681-6. doi:10.2147/NDT.S58059. Published 2014 Apr 28.

64. Fukutomi M, Yokota M, Chuman $\mathrm{H}$, et al. Increased incidence of bone metastases in hepatocellular carcinoma. Eur J Gastroenterol Hepatol. 2001;13(9):1083-8. doi:10.1097/00042737-200109000-00015.

65. Murakami R, Korogi Y, Sakamoto Y, et al. Skull metastasis from hepatocellular carcinoma. CT, MR and angiographic findings. Acta Radiol. 1995;36(6):597-602. 
66. Subasinghe D, Keppetiyagama CT, Sudasinghe H, Wadanamby S, Perera N, Sivaganesh S. Solitary scalp metastasis - a rare presentation of hepatocellular carcinoma. Ann Surg Innov Res. 2015;9:4. doi:10.1186/s13022-015-0013-2. Published 2015 Jun 9.

\section{Tables}

Due to technical limitations, table 1 is only available as a download in the Supplemental Files section.

\section{Figures}

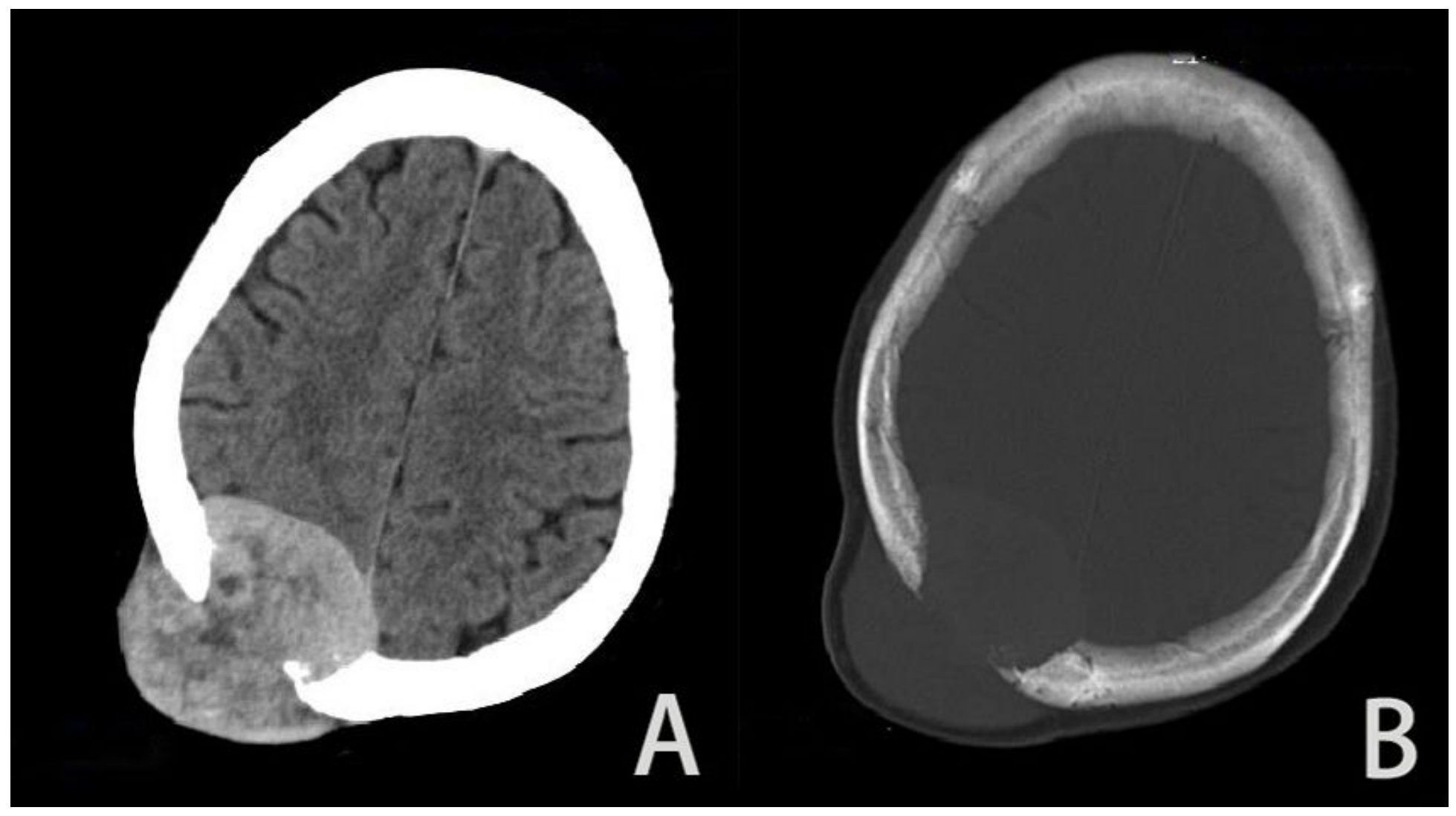

Figure 1

CT plain scan of the skull showed a mass of occipital mass with a slightly higher density (Fig. A), $6.4 \times 5.6 \mathrm{~cm}$ in diameter, exhibiting a clear boundary of the mass, uneven internal density, growth across the skull and displacement near the brain parenchyma. Bone window (Fig. B) indicated local bone destruction of the right parietal bone. 


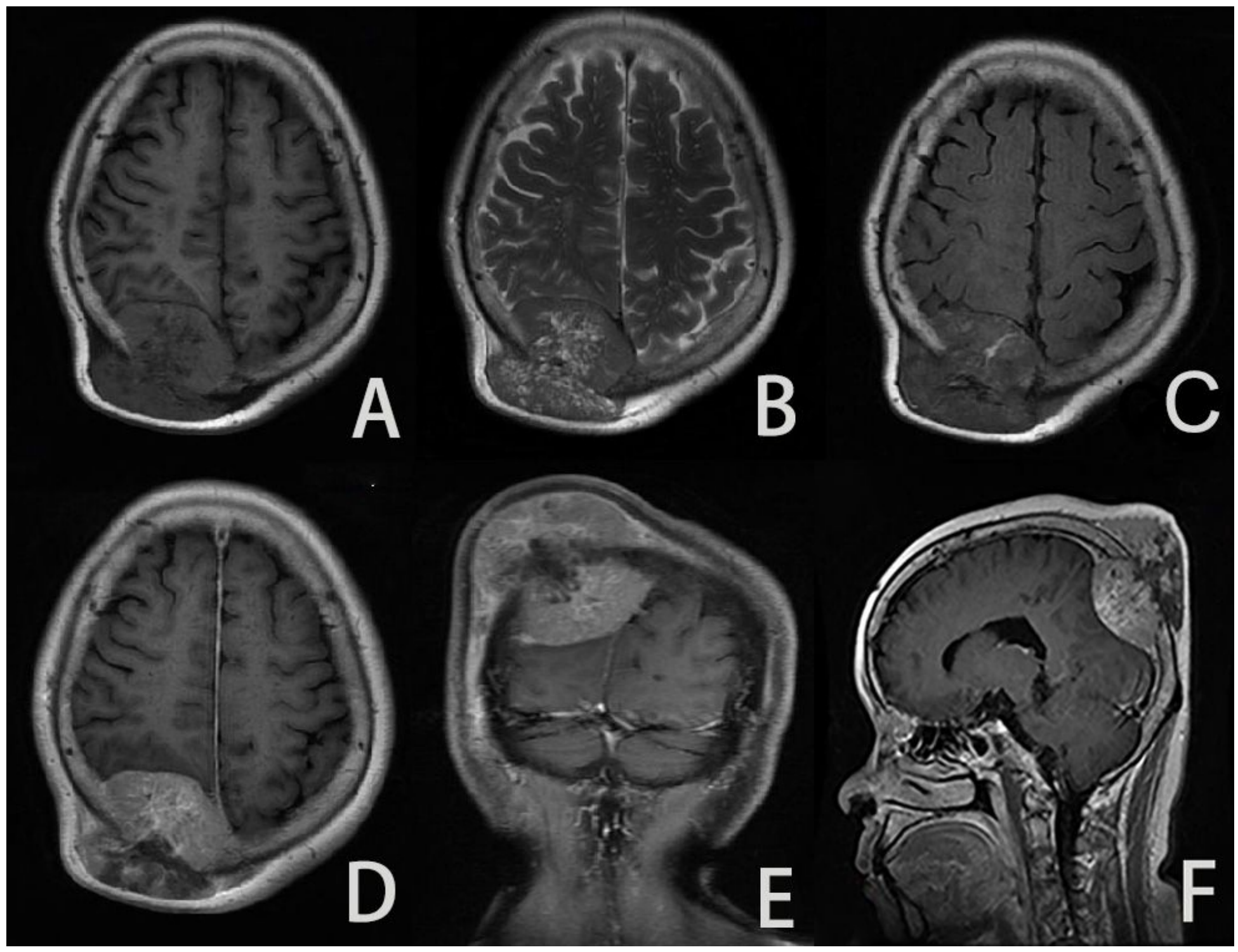

\section{Figure 2}

Magnetic resonance imaging of the brain showed an occipital mass. T1WI (Fig. A,) ; T2WI (Fig. B,) ; FLAIR (Fig. C,). An internal slice of long T2 signal found clear transcranial growth, no brain edema, and destruction of the local skull. After the contrast, (Figure D-F,) significant uneven enhancement of mass Axial, coronal, sagittal T1 enhanced. The adjacent meninges were enhanced. 


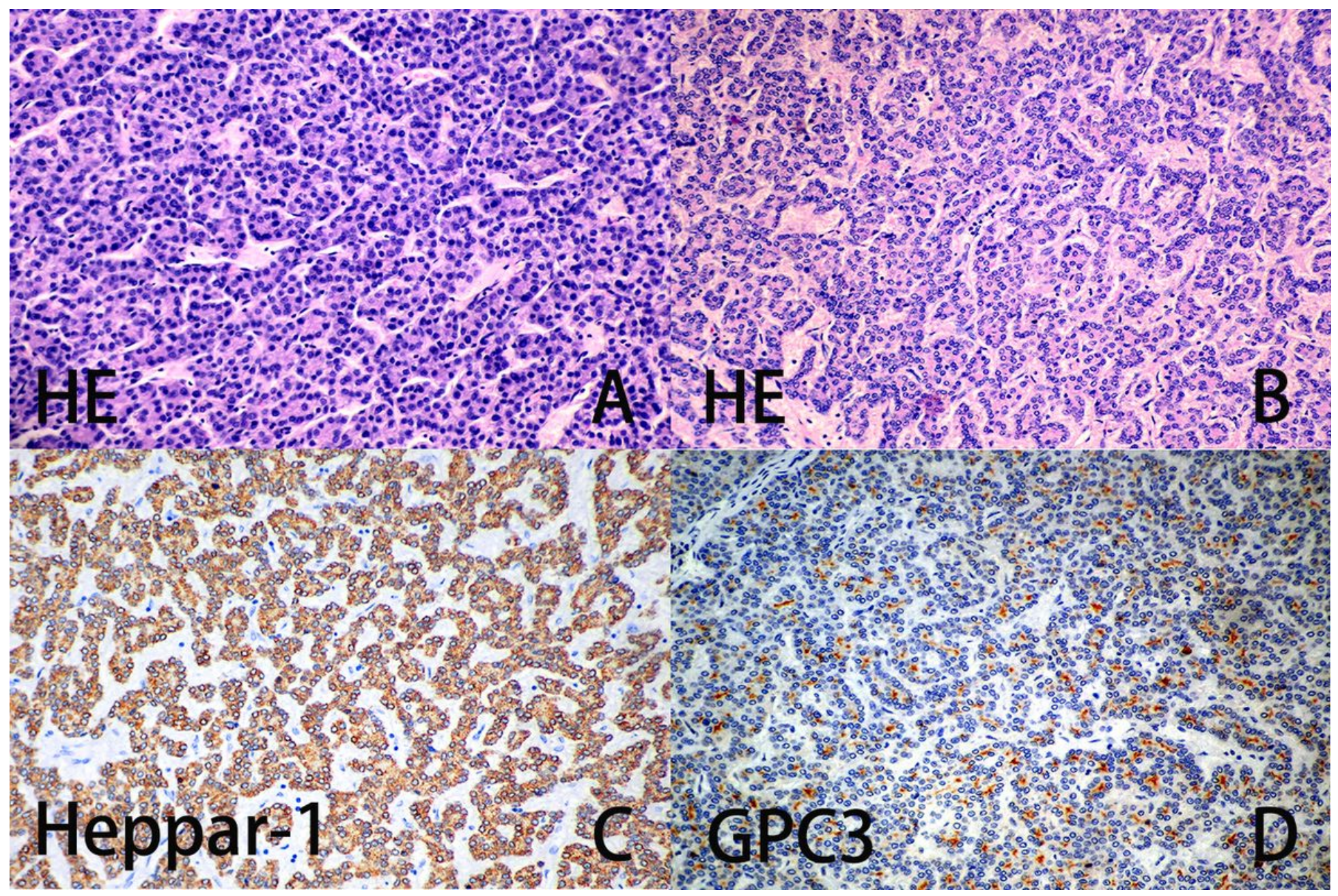

\section{Figure 3}

Postoperative immunohistochemistry analysis suggested metastatic hepatocellular carcinoma. (Fig. A. B. HE stains; Fig. C Heppar-1; Fig D. GPC3)

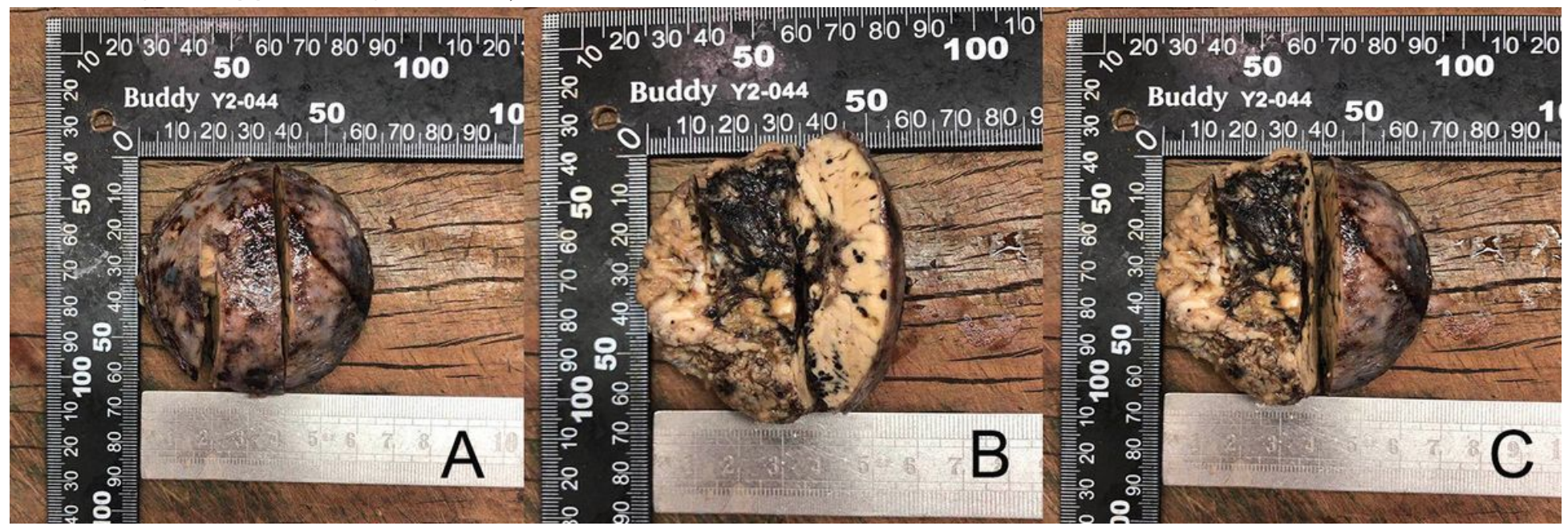

Figure 4

An oblate mass sized of $6.7 \times 6.7 \times 2 \mathrm{~cm}$ is visible to the naked eye. The cut surface seemed grayish yellow and dark red, and the capsule was intact. (Figure A, B, C). 


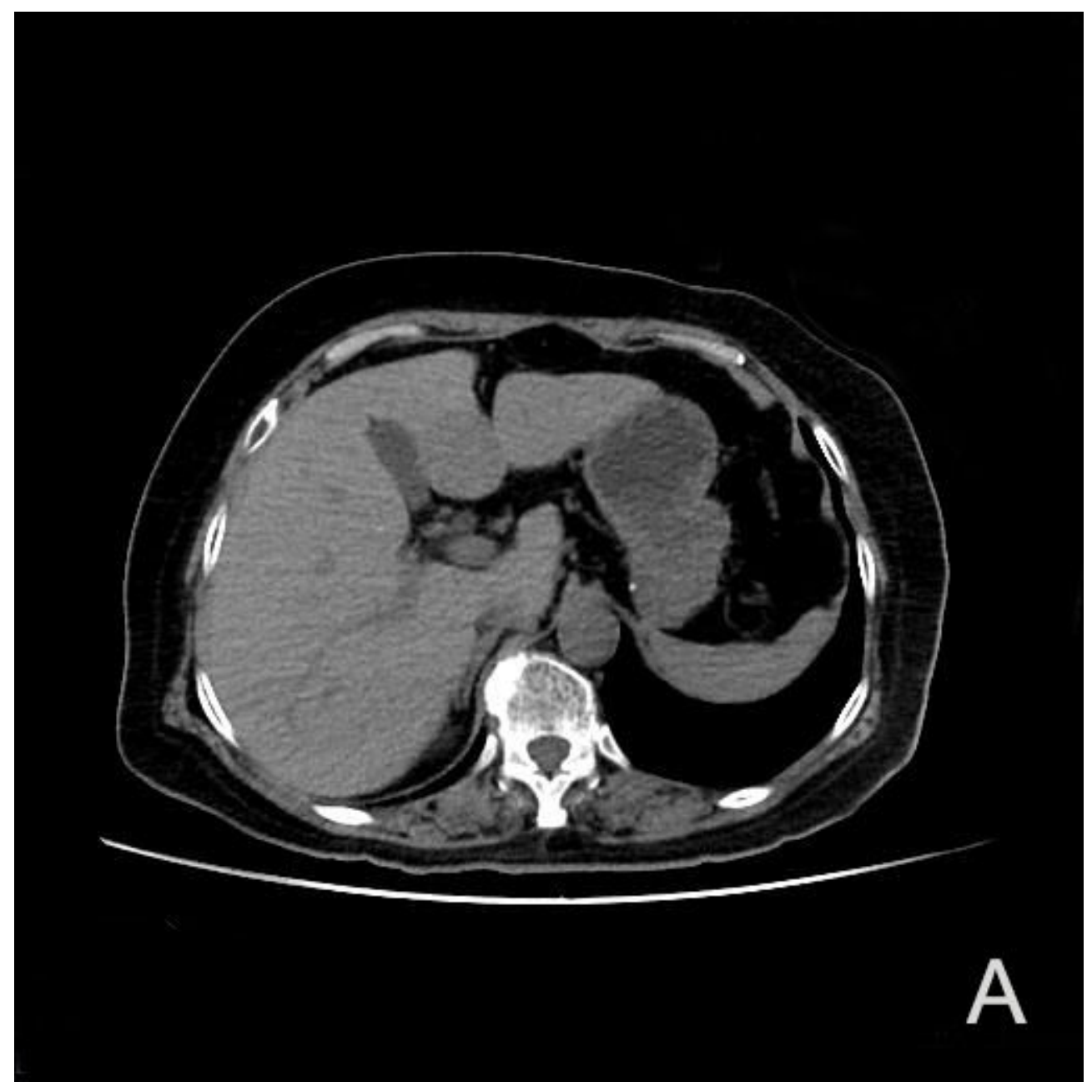

\section{Figure 5}

CT image observed a nodule sized of $3.8 \mathrm{~cm}$ in diameter in the left lobe of the liver. Enhanced scanning found that the arterial phase was enhanced, and that the portal and venous phases showed relatively low density. These finds were indicative of liver cancer.

\section{Supplementary Files}

This is a list of supplementary files associated with this preprint. Click to download.

- table.xlsx 